\title{
$\mathrm{PH}$
}

panorama

\section{El Cabanyal, un patrimonio rescatado por la ciudadanía}

\begin{abstract}
El Cabanyal es un barrio histórico de Valencia amenazado por un proyecto urbanístico que ha sido frenado gracias a la movilización ciudadana en un largo conflicto desarrollado entre los años 1998 y 2015 . Fruto de esta lucha es el proyecto Cabanyal Archivo Vivo, que desde 2011 aglutina un conjunto de acciones de sensibilización y visualización de dicha problemática. El pasado mes de abril, la presidenta de la Asociación de Vecinos Cabanyal-Canyamelar, María José Dasi, recogía el galardón del Premio Unión Europea de Patrimonio Cultural/Europa Nostra 2013 concedido al proyecto Cabanyal Archivo Vivo en la categoría de educación, formación y sensibilización.
\end{abstract}

\section{Emilio Martínez Arroyo, Fabiane C. S. Dos Santos | Universidad Politécnica de Valencia}

URL de la contribución <www.iaph.es/revistaph/index.php/revistaph/article/view/3659>

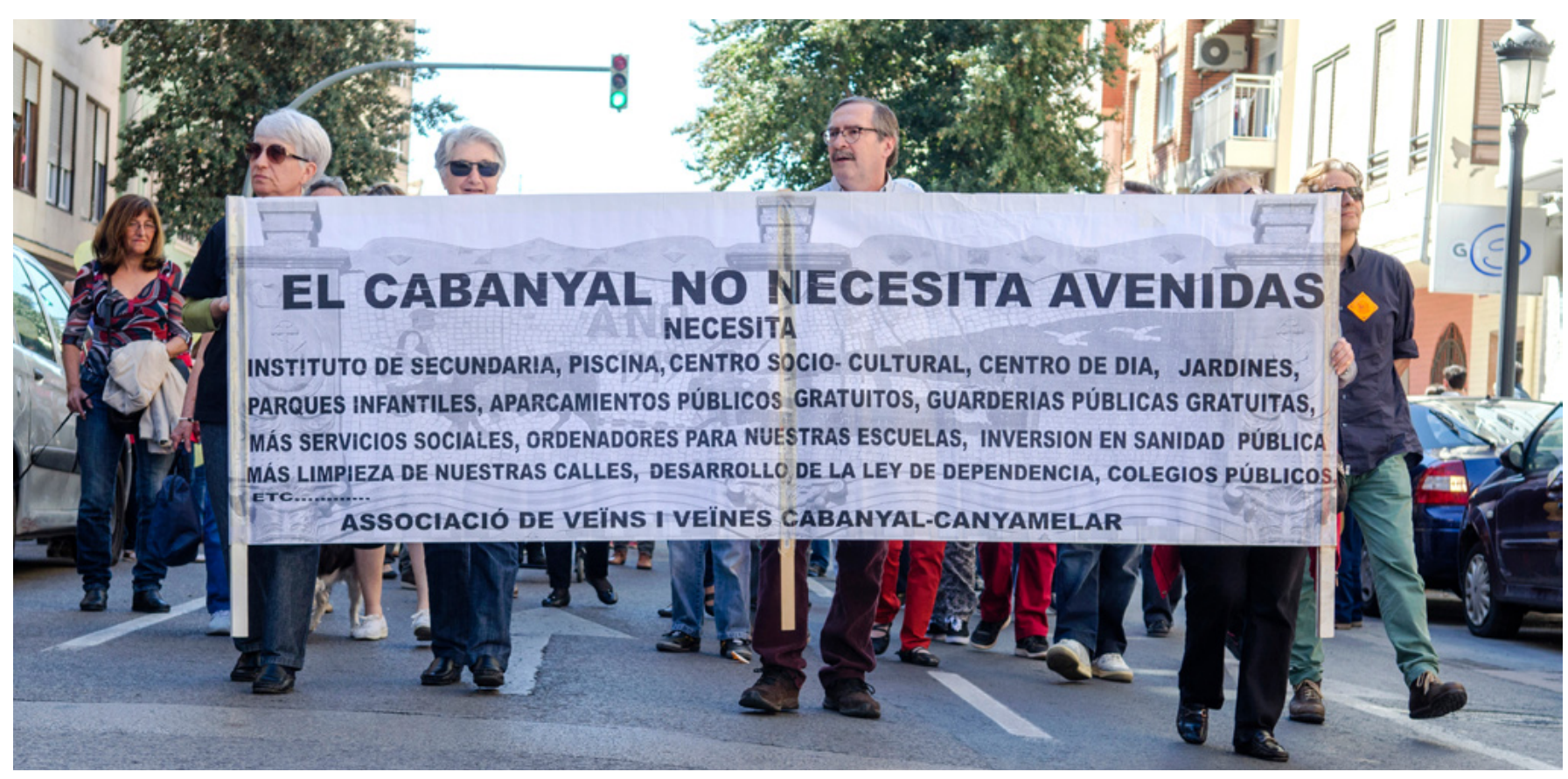

Asociación de vecinos del Cabanyal clamando con una pancarta lo que necesita el barrio tomada el 6 de abril de 2014 | foto Carmen Tolsa Rovira de Imagen en Acción

El Cabanyal, antiguo barrio marinero y portuario de la ciudad de Valencia, ha sufrido en el periodo 1998-2015, la mayor amenaza de destrucción de su historia. El periodo del desarrollismo en la historia española ha dejado una desafortunada huella en la imagen de nuestras ciudades, en el contexto de las ciudades de los años 50 y 60 , que todavía conservaban una imagen propia del aislamiento en el que vivía el país y la sociedad española de la época. Ciudades que a pesar de su provincianismo habían mantenido buena parte de su patrimonio arquitectónico. El empuje constructor e inmobiliario de finales de los 60 y 70 inundó las periferias pero también los centros históricos de nuevas edificaciones sin ninguna consideración con el entorno -alineaciones de altura, estilo arquitectónico, etc.- ante el desinterés de las instituciones por la protección del patrimonio entendido como conjuntos históricos, más allá de inmuebles singulares. Es pues coincidiendo con el advenimiento del sistema 
democrático cuando empiezan a protegerse los centros históricos con un nuevo planteamiento acorde con los principios que ya imperaban en toda Europa en la protección del patrimonio arquitectónico y urbanístico de las ciudades.

En este nuevo contexto democrático es cuando se inicia un proceso de estudio y protección de distintos centros históricos de la ciudad de Valencia, concretamente el Cabanyal es declarado BIC (bien de interés cultural) en 1993, por el valor tanto de sus edificios de modernismo popular como por su trama en retícula característica y testigo de su ampliación urbanística por el crecimiento de la playa, consecuencia de la acción del puerto de la ciudad, que produce la ampliación de las playas situadas a su norte y la disminución de las del sur y que han hecho que, desde que tenemos constancia a través de imágenes y mapas históricos ${ }^{1}$, la playa se haya retirado más de 700 metros con la consiguiente urbanización del antiguo Pueblo Nuevo del Mar, actualmente el Cabanyal.

Pues bien, es por todo ello que parecía inviable que el partido político (PP) en el gobierno (1991-2015) de la ciudad de Valencia pudiera plantear una intervención sobre el barrio, eufemísticamente llamada en un principio PEPRI, Plan de protección y reforma interior, del Cabanyal que suponía atravesarlo transversalmente por una avenida, en una intervención de 150 metros de ancho y la consiguiente demolición de 1.651 viviendas. Ante semejante atropello por parte de las autoridades que tienen la responsabilidad de la protección de nuestro patrimonio histórico, se inició un largo proceso que ha durado 17 años (1998-2015) por parte de la ciudadanía articulada en torno al movimiento Salvem el Cabanyal, de defensa y concienciación ciudadana sobre esta situación y por extensión sobre la gestión de todo nuestro patrimonio histórico. Lucha que se ha desarrollado todos estos años tanto en el terreno de la movilización ciudadana, como en el ámbito jurídico. Un amplísimo litigio que se solucionó cuando los tribunales admitieron que el patrimonio del Cabanyal era de todos los valencianos en la misma medida que era y es de todos los españoles, por lo que si bien el gestor y responsable de la protección de este patrimonio son las instituciones locales y autonómicas, el garante final, ante el posible atropello o expolio que pudiera sufrir este patrimonio, es el propio Ministerio de Cultura que garantiza la protección e integridad de todo el patrimonio español.

En este contexto, el Ministerio de Cultura, gestionado por el gobierno del PSOE en ese momento, inicia una serie de acciones de concienciación sobre el patrimonio del Cabanyal, encargando a la Asociación La Esfera Azul un proyecto en este sentido. La presidenta de la Esfera Azul, Lupe Frigols, se pone en contacto con la asociación de vecinos del Cabanyal y con el movimiento ciudadano que había estado luchando todos estos años en la dirección de defensa de los valores patrimoniales del barrio; y, particularmente, con Bia Santos y Emilio Martínez, por nuestra implicación con uno de los proyectos singulares que había desarrollado la plataforma Salvem el Cabanyal anualmente, que era Cabanyal Portes Obertes, en el que los propios vecinos abrían sus casas particulares a toda la ciudad para albergar en ellas temporalmente las obras de los artistas que querían mostrar su solidaridad con el Cabanyal y denunciar la actitud de la administración local de la época.

Se abrió con la propuesta de la Esfera Azul la posibilidad de colaborar con la administración, por primera vez en 12 años de lucha, en un proyecto de valorización del barrio en la misma línea que veníamos defendiendo desde 1998, aún contando con la oposición del partido (PP) que ostentaba la mayoría absoluta tanto en la ciudad de Valencia como en la Comunidad Valenciana en aquel momento. Ante la inestabilidad de la situación política y la temporalidad intrínseca a su naturaleza, planteamos que este proyecto debería abordarse como un espacio de reflexión, divulgación y visibilización de la problemática más allá del límite temporal en el que se desarrollase (2011) y permitiera convertirse en un herramienta al servicio de estos valores y a disposición de la ciudadanía, resistente a los intereses y alcances de las fuerzas políticas adversas a la conservación y rehabilitación del Cabanyal. Así pues propusimos la creación de un archivo digital "Cabanyal Archivo Vivo", compuesto por una serie de proyectos dirigidos a diversos ámbitos (pedagógico, social, artístico, patrimonial arquitectónico y urbanístico), que permitiera convertirse en una plataforma de acción y divulgación como así ha sido hasta 
el momento presente, sin necesidad de financiación ni dependencia externa. Como se expone en la presentación de la página web del proyecto:

"Inicialmente Cabanyal Archivo Vivo, es un conjunto de acciones en el espacio real y en internet, que abarcan el ámbito pedagógico (con la realización de un material sobre el patrimonio arquitectónico y cultural del barrio), social (encuentros y mesas redondas con especialistas y asociaciones vecinales del litoral marítimo) y proyectos artísticos (una serie de propuestas a partir de conceptos de geolocalización y la edición de un número especial de la revista 'la más bella')"2.

La brevedad de este escrito impide una descripción pormenorizada del proyecto. Pueden acceder a él a través de la comunicación "Una herramienta de resistencia. Cabanyal Archivo Vivo: el archivo digital como estrategia de resistencia frente a las inercias urbanísticas de destrucción del patrimonio"3, con una descripción de los objetivos y resultados alcanzados así como de unas conclusiones provisionales:

"En el proceso de destrucción y empobrecimiento que se ha producido en la misma expansión de las ciudades y de su implosión. Los centros históricos se han convertido en un objeto de deseo para especuladores y gestores públicos y no siempre con el objetivo de generar mejores condiciones de vida, o equipamientos para el bien común. En este ámbito resultan importantes las naturalezas de las políticas que se ponen en marcha. La tentación de los gestores públicos en la actitud impositiva de sus decisiones es sacralizada por su parcial visión de las prácticas democráticas, según la cual la mera ratificación en las urnas de sus personas es suficiente control para legitimar sus decisiones.

Este déficit del proceso democrático que se manifiesta claramente en nuestra sociedad, ha sido desde hace tiempo abordado en aquellas sociedades en las que la práctica democrática y su desarrollo están interiorizadas de tal manera que han pasado a formar parte de su propia naturaleza. Conceptos como participación ciudadana que en nuestro contexto son una excepción cuando no una quimera, son en estas sociedades avan-

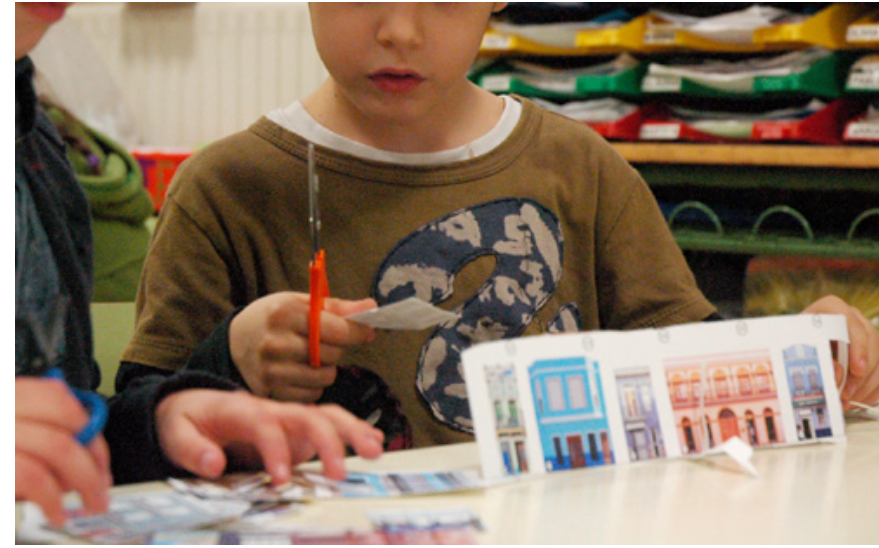

Proyecto "Aprendiendo del Cabanyal" de Silvia Molinero y Mixuro, estudio de arquitetura | foto Silvia Molinero

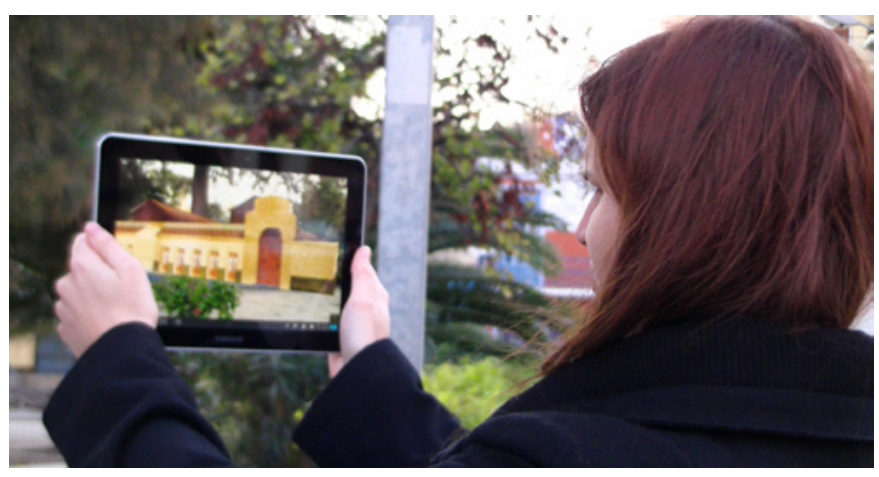

Proyecto "TimetravellersCabanyal" de Manusamo\&Bzika | foto Bia Santos

zadas democráticamente práctica común al abordar las intervenciones urbanísticas, no siempre resueltas sin confrontaciones o conflictos, pero si en la mayor parte de las ocasiones permeables o dispuesta a un feedback entre los distintos interlocutores.

Cabanyal Archivo Vivo permite un trabajo continuo en el tiempo y se convierte en una herramienta que da voz a los ciudadanos y los colectivos sociales frente a los abusos de la administración pública y de los intereses de los grandes grupos financieros inmobiliarios presentes en la ciudad." [sic] (MARTíNEZ; DOS SANTOS, 2014: 701).

Posteriormente, Cabanyal Archivo Vivo obtuvo el reconocimiento internacional con el Premio Unión Europea de Patrimonio Cultural/Europa Nostra 2013, en la categoría de educación, formación y sensibilización por (en palabras del jurado): "la importancia de la iniciativa ciu- 
dadana cuando es consciente de su responsabilidad con respecto al patrimonio cultural tanto a nivel urbano o de calle, como a mayor escala arquitectónica y social. El proyecto muestra, de manera ejemplar, hasta qué punto se puede despertar la sensibilidad de los ciudadanos hacia el frente marítimo histórico de Valencia, a través de una planificación urbana sostenible, basada en la identidad cultural y en la participación".

En la actualidad un cambio decisivo se ha producido El Cabanyal. El Partido Popular ha perdido el gobierno de la ciudad; un nuevo equipo comprometido con el desarrollo y rehabilitación del Cabanyal ha empezado a trabajar en esta dirección. Los principios que reclamamos en su día y que defendemos en la actualidad están empezando a implementarse y abren una nueva etapa que han hecho de lo utópico lo posible y necesario para un futuro mejor para todos en el Cabanyal, y además tampoco costaba tanto. Todavía es pronto para valoraciones pero desde la ciudadanía seguiremos atentos, colaborativos, esperanzados y críticos para que la situación que hemos pasado en el Cabanyal no vuelva a producirse.

\section{NOTAS}

1. Existen imágenes panorámicas del litoral de Valencia, Cabanyal incluido, obra de Anthoine Van den Wijngaerde, fechados en 1563.

2. http://www.cabanyalarchivovivo.es/que_es_archivo. html [Consulta: 10/07/2015]

3. Publicada en las Actas del II Congreso Internacional de Educación Patrimonial (28-31 de octubre de 2014) (MARTÍNEZ; DOS SANTOS, 2014).

\section{BIBLIOGRAFÍA}

- AA. VV. (2001) Modos de hacer. Arte crítico, esfera pública y acción directa. Salamanca: Universidad, 2001

- CARRILlo, J. (2004) Arte en la red. Madrid: Cátedra, 2004

- DEBORD, G. (1967) La sociedad del espectáculo. Valencia: Pre-textos, 1967

- DElgado, M. (1999) El animal Público. Barcelona: Anagrama, 1999

- DUQUE, F. (2001) Arte Público y Espacio político. Madrid: Akal, 2001

- FOUCAULT, M. (1982) El sujeto y el poder en Arte después de la modernidad. Madrid: Akal, 1982

- MARTÍNEZ, E.; DOS SANTOS, F. (2014) Una herramienta de resistencia. Cabanyal Archivo Vivo: el archivo digital como estrategia de resistencia frente a las inercias urbanísticas de destrucción del patrimonio. En Actas del II Congreso Internacional de Educación Patrimonial. 28-31 Oct 2014. Madrid: IPCE/OEPE, pp. 689-702

- PRADA, J. M. (2012) Otro Tiempo para el Arte. Valencia: Sedemá, 2012

- WOLFF, J. (1997) La producción social del arte. Madrid: Istmo, 1997 